Henry Searby, and Fred Colahan; lobectomy by Sir Henry Newland and Mr. Brown himself; the first closure of a patent ductus arteriosus in Australia by Ben Edye in Sydney in 194I; shunt operations for Fallot's tetralogy in 1947; shunt operations for coarctation of the aorta in 1948 at the Alfred Hospital; the introduction of mitral valvotomy to Australia by Frank Mills of Sydney; the introduction of hypothermia to Australia at the Royal Children's Hospital, Melbourne, by Russell Howard in 1955, and the first use in this country of the pump oxygenator to close a ventricular septal defect by Kenneth Morris at the Alfred Hospital in 1957.

The meeting of the Section held on Monday, 8 September 1958, was devoted to the exhibition by the President, Professor K. Russell, of a large series of lantern slides dealing with illuminated medical manuscripts and other matters of artistic and historical interest.

\title{
NORWEGIAN SOGIETY FOR THE HISTORY OF MEDICINE
}

A the meeting held on 6 November 1958, the Chairman, Professor Axel Stroem, M.D., gave a survey of the activities of the Society since its foundation in 1956 . Professor Stroem was re-elected Chairman and Bernhard Getz, M.D., Anatomical Institute, University of Oslo, continues to hold the office of Secretary.

Professor Niels Danbolt read a paper dealing with three outstanding Norwegian physicians by the name of Boeck, namely the physiologist Peter Bianco Boeck (1798-1877) and the dermatologists Carl Wilhelm Boeck (1808-75) and Caesar Boeck (1845-191 7). Professor Danbolt gave an interesting survey of the Boeck family and its participation in Norwegian cultural life during the nineteenth century. The Boecks contributed not only to medical science, but also took an active part in botanical studies and in politics.

Peter Bianco Boeck was the first lecturer in physiology at the University of Oslo, and he was also appointed lecturer in veterinary diseases. Wilhelm Boeck is known outside Norway for his famous contributions to the understanding of leprosy (on which he worked with Danielssen) and for his peculiar treatment of syphilis, the so-called 'syphilization'. This therapeutic method was demonstrated for British physicians during a visit to one of the London hospitals for venereal diseases and also to Sir Johnathan Hutchinson during his stay in Norway.

Caesar Boeck was professor of dermatology at the University of Oslo from 1895 to 1915, succeeding his uncle Wilhelm Boeck. He was an outstanding teacher and also made important contributions to dermatology. His name is widely known in connexion with the so-called benign multiple sarcoidosis, a disease of which he gave a detailed and classical description both with regard to the clinical and histological picture. Professor Boeck also took a great interest in art, especially in painting, and wrote noteworthy articles on this subject.

BERNHARD GETZ 